\title{
Bacteriological profile of wound infection and antibiotic susceptibility pattern of the isolates
}

\begin{abstract}
Introduction: Wound infection is the one of the most important causes of morbidity and mortality worldwide and antibiotics resistant bacteria are the great part of complications on treatment of the infection.

Objectives: The present study was conducted to isolate and identify the etiological agents of wound infection and assess the antimicrobial susceptibility pattern of the isolates.

Methods: The study was carried out on wound infection suspected patients visiting B and B Hospital for six months duration. The collected pus specimen were first observed macroscopically then streaked on MacConkey agar and blood agar, incubated at 370C for 24 hours. The isolated bacteria were identified by macroscopic and microscopic observations and biochemical reactions. Antibiotic susceptibility pattern of the isolates was assessed by Modified Kirby Baur disc diffusion technique.

Results: A total of 503 pus samples were collected; of which $43.7 \%$ showed bacterial growth. Out of a total 220 bacterial isolates; $158(71.82 \%)$ were Gram negative and 62 $(28.18 \%)$ were Gram positive bacteria. Pseudomonas spp. $(34.55 \%)$ was most common followed by Staphylococcus aureus (21.36\%), Escherichia coli (11.82\%), Acinetobacter baumannii (11.36\%), Enterobacter aerogens (8.18\%), Coagulase negative Staphylococci (CoNS) (5.45\%), Klebsiella pneumoniae (4.55\%), Citrobacter freundii (1.36\%), Streptococcus spp. (0.91\%) and Enterococcus spp. (0.46\%). Most of Gram negative bacteria (63.9\%) and Gram positive bacteria (93.5\%) were susceptible to amikacin and chloramphenicol respectively. Among 220 isolates, 138 (62.73\%) were found to be multi drug resistant (MDR). All the isolates of $A$. baumannii were isolated from inpatients and almost $96.4 \%(24 / 25)$ were MDR.
\end{abstract}

Conclusion: In this study, significant number of MDR strains was found as the causative agent of wound infection. So, routine microbiological analysis of the wound specimen and their antibiotic susceptibility testing are recommended that will guide medical practitioners for empirical treatment of wound infection, so as to reduce the spread of resistant bacteria.
Volume 4 Issue 5 - 2017

\author{
Mahat P,' Manandhar S,' Baidya Baidya² \\ 'Department of Microbiology, National College, Nepal \\ ${ }^{2} \mathrm{~B}$ and $\mathrm{B}$ Hospital, Nepal
}

Correspondence: Pushpa Mahat, Department of Microbiology, National College, Khusibu, Kathmandu,

Emailmahatpusphal@gmail.com

Received: June 29, 2016 | Published: April 17, 2017

Keywords: wound infection, antibiotic susceptibility, MDR

\section{Introduction}

The exposure of subcutaneous tissue following a loss of skin integrity (i.e. a wound) provides a moist warm and nutritive environment that is conducive to microbial colonization and proliferation. The progression of a wound to an infected state is likely to involve a multitude of microbial and host factors. ${ }^{1}$ Wound can be infected by a variety of microorganisms ranging from bacteria to fungi and parasites as well as virus. ${ }^{2}$ The most common organisms are $S$. aureus, P. aeruginosa, E. coli, Klebsiella spp. and Acinetobacter spp..$^{3,4}$

Antibiotics, although, have been of great value in treatment and in prophylaxis to prevent infections, the timing of administration, choice of antimicrobial agent, durations of administration have clearly defined the value of antibiotics in reducing wound infections. ${ }^{5}$ Advance in control of infection have not completely eradicated the problem of the wound infection because of development of drug resistance. ${ }^{6}$

Wound infection results in sepsis, limb loss, long hospital stays, higher costs and is responsible for significant human mortality and morbidity worldwide. ${ }^{7}$ It is one of the most common hospital acquired infections. ${ }^{8}$ It remains an ongoing problem which although, cannot be completely eradicated however, by taking prompt control measures against the most commonly isolated organism and proper care of wound may lead to the minimum of wound infection. ${ }^{1}$ Hence, the present study was carried out to identify the causative agent of wound infection and antibiotic susceptibility pattern of the isolates, which will be beneficial as guidance for medical practitioners to select empirical antimicrobial therapy and on the implementation of infection control measures that plays an important role in minimizing the emergence rate of antimicrobial resistance (MDR).

\section{Methods}

A cross-sectional study was carried out in a total of 503 aseptically collected pus samples from wound infection suspected patients visiting B and B hospital, Lalitpur from October 2013 to April 2014. The pus specimen were macroscopically analyzed for their color and odor then were streaked on MacConkey agar and Blood agar plates and incubated at $370 \mathrm{C}$ for 24 to 48 hours. All the isolates were identified by colony morphology, staining reaction and the biochemical properties. ${ }^{9}$ The antimicrobial susceptibility test of isolates was performed by Modified Kirby Bauer disc diffusion method using the standard guidelines of the ${ }^{10}$ and MDR strain was identified as resistant to $\geq 3$ antimicrobial classes. ${ }^{11}$ The computer data were studied using 
the statistical software SPSS version 17. Chi-square test was used to calculate probabilities and determine significance. A p-value of less than or equal to 0.05 was considered to be statistically significant $\mathrm{p}<0.05)$.

\section{Results}

Out of 503 pus samples from wound infection suspected patients, $220(43.7 \%)$ showed bacterial growth whereas 283 (56.3\%) were growth negative (Table 1). Out of 302 samples from in-patients, $160(53.0 \%)$ samples and among 201 samples from out patients, 60 (29.9\%) samples showed bacterial growth. The higher percentage of culture positivity seen among in-patients was found to be statistically significant $(\mathrm{P}<0.001)$ (Table 2).

Table I Growth pattern of Bacteria

\begin{tabular}{|llll}
\hline S. No. & Growth & No. of samples & \% of samples \\
\hline I & Culture positive & 220 & 43.7 \\
\hline 2 & Growth negative & 283 & 56.3 \\
& Total & 503 & 100 \\
\hline
\end{tabular}

Table 2 Distribution of growth positive cases in in-patient and out-patient

\begin{tabular}{|c|c|c|c|c|c|c|}
\hline \multirow{2}{*}{ Patient type } & \multicolumn{2}{|c|}{ Growth } & \multicolumn{2}{|c|}{ No growth } & \multirow{2}{*}{ Total } & \multirow{2}{*}{ P-Value } \\
\hline & No. & $\%$ & No. & $\%$ & & \\
\hline In-patient & 160 & 53 & 142 & 47 & 302 & 0.001 \\
\hline Out-patient & 60 & 29.9 & $|4|$ & 70.1 & 201 & \\
\hline Total & 220 & 43.7 & 283 & 56.3 & 503 & \\
\hline
\end{tabular}

Among 370 (73.56\%) male patients and 133 (26.44\%) female patients, $172(46.50 \%)$ and $48(36.1 \%)$ were found growth positive respectively. The result was statistically significant $(\mathrm{P}=0.038)$ (Table 3). Among 220 positive cases the highest positive cases 67 (30.45\%) was found in the patients of age group 21-30 years (Table 4).

Table 3 Gender-wise distribution of growth positive cases

\begin{tabular}{|c|c|c|c|c|c|c|}
\hline \multirow{2}{*}{ Patient type } & \multicolumn{2}{|c|}{ Growth } & \multicolumn{2}{|c|}{ No Growth } & \multirow{2}{*}{ Total } & \multirow{2}{*}{ P-Value } \\
\hline & No. & $\%$ & No. & $\%$ & & \\
\hline Male & 172 & 46.5 & 198 & 53.5 & 370 & 0.038 \\
\hline Female & 48 & 36.1 & 85 & 63.9 & 133 & \\
\hline Total & 220 & 43.7 & 283 & 56.3 & 503 & \\
\hline
\end{tabular}

Among 220 bacterial isolates, Gram negative bacteria were predominant with $158(71.82 \%)$ isolates, while Gram positive bacteria contributed $62(28.18 \%)$ of total isolates. Altogether 10 different bacterial species were isolated, among which Pseudomonas spp. $(34.55 \%)$ were predominant followed by $S$. aureus $(21.36 \%)$ (Table 5 ). Out of 220 isolates, most of the isolates were isolated from in-patient (72.73\%) than out-patient (27.27\%). All the A. baumannii were from in-patients (Table 6).

Vancomycin was used only for the isolates resistant to cloxacillin. Most of the Gram positive bacterial isolates (more than 90\%) were found to be sensitive to chloramphenicol. Penicillin G was ineffective $(100 \%)$ to all the Gram positive isolates followed by amoxycillin (Table 7). Most of the Gram negative bacterial isolates (more than $48 \%$ ) were found to be sensitive to amikacin, gentamicin and cefoperazone/ sulbactum whereas $73.4 \%$ of them were resistant to ciprofloxacin (Table 8).

Table 4 Age and Gender-wise distribution of growth positive cases

\begin{tabular}{lllllll}
\hline Age group(Yrs) & Male total & Positive & Female total & Positive & Total cases & Total positive cases \\
\hline I $\leq 10$ & 21 & 7 & 13 & 4 & 34 & $1 \mathrm{II}(5 \%)$ \\
$20-$ Nov & 74 & 43 & 7 & 1 & 81 & $44(20 \%)$ \\
$21-30$ & 82 & 50 & 36 & 17 & 118 & $67(30.45 \%)$ \\
$31-40$ & 61 & 25 & 30 & 14 & 91 & $39(17.73 \%)$ \\
$41-50$ & 56 & 18 & 16 & 3 & 72 & $21(9.55 \%)$ \\
$51-60$ & 41 & 21 & 12 & 2 & 53 & $23(10.45 \%)$ \\
$61-70$ & 16 & 2 & 11 & 4 & 27 & $6(2.73 \%)$ \\
$\geq 71$ & 19 & 6 & 8 & 3 & 27 & $9(4.09 \%)$ \\
Total & 370 & 172 & 133 & 48 & 503 & 220 \\
\hline
\end{tabular}

Table 5 Distribution of bacterial isolates

\begin{tabular}{lll}
\hline Organism & No of isolates (\%) & \% of Total isolates \\
\hline Gram Positive Bacteria & & \\
S. aureus & $47(75.81)$ & 21.36 \\
CoNS & $12(19.35)$ & 5.45 \\
Streptococcus spp. & $2(3.23)$ & 0.91 \\
Enterococcus spp. & $1(1.61)$ & 0.46 \\
Total & $62(100)$ & 28.18 \\
Gram Negative Bacteria & & \\
Pseudomonas spp. & $76(48.10)$ & 34.55 \\
E. coli & $26(16.46)$ & 11.82 \\
Acinetobacter baumannii & $25(15.82)$ & 11.36 \\
E. aerogens & $18(11.39)$ & 8.18 \\
K. pneumoniae & $10(6.33)$ & 4.55 \\
C. freundii & $3(1.90)$ & 1.36 \\
Total & $158(100)$ & 71.82 \\
\hline
\end{tabular}


Table 6 Distribution of isolates among in-patient and out-patient

\begin{tabular}{llllll}
\hline \multirow{2}{*}{ Organisms } & In patient & \multicolumn{3}{c}{ Out patient } & Total \\
\cline { 2 - 5 } & Frequency & $\%$ & Frequency & $\%$ & \\
\hline S. aureus & 23 & 48.9 & 24 & 51.1 & 47 \\
CoNs & 8 & 66.7 & 4 & 33.3 & 12 \\
Streptococcus spp. & 2 & 100 & 0 & 0 & 2 \\
Enterobacter spp. & 1 & 100 & 0 & 0 & 1 \\
Pseudomonas spp. & 58 & 76.3 & 18 & 23.7 & 76 \\
E. coli & 20 & 76.9 & 6 & 23.1 & 26 \\
Acinetobacter baumannii & 25 & 100 & 0 & 0 & 25 \\
E. aerogens & 14 & 77.8 & 4 & 22.2 & 18 \\
K. pneumoniae & 7 & 66.7 & 3 & 30.3 & 10 \\
C. freundii & 2 & 66.7 & 1 & 33.3 & 3 \\
Total & 160 & 72.73 & 60 & 27.27 & 220 \\
\hline
\end{tabular}

Table 7 Antibiotic susceptibility pattern of Gram positive isolates

\begin{tabular}{llllllll}
\hline \multirow{2}{*}{ Antibiotics } & \multicolumn{2}{l}{ Sensitive } & \multicolumn{2}{l}{ Intermediate } & \multicolumn{2}{l}{ Resistant } & \multirow{2}{*}{ Total } \\
\cline { 2 - 7 } & No. & $\%$ & No. & $\%$ & No. & $\%$ & \\
\hline Ciprofloxacin & 27 & 43.5 & 7 & 11.3 & 28 & 45.2 & 62 \\
Ofloxacin & 27 & 43.5 & 7 & 11.3 & 28 & 45.2 & 62 \\
Ceftiraxone & 46 & 74.2 & 6 & 9.7 & 10 & 16.1 & 62 \\
Gentamicin & $4 I$ & 66.1 & I & 1.6 & 20 & 32.3 & 62 \\
Chloramphenicol & 58 & 93.5 & I & 1.6 & 3 & 4.8 & 62 \\
Cefoperazone/ Sulbactam & 31 & 86.11 & I & 2.78 & 4 & 11.11 & 36 \\
Penicillin G & 0 & 0 & 0 & 0 & 62 & 100 & 62 \\
Amoxycillin & II & 17.7 & 0 & 0 & 51 & 82.3 & 62 \\
Erythromycin & 29 & 46.8 & 5 & 8.1 & 28 & 45.2 & 62 \\
Clindamycin & 54 & 91.53 & 0 & 0 & 5 & 8.47 & 59 \\
Cloxacillin & 56 & 94.92 & 0 & 0 & 3 & 5.08 & 59 \\
Vancomycin & 5 & 100 & 0 & 0 & 0 & 0 & 5 \\
\hline
\end{tabular}

Table 8 Antibiotic susceptibility pattern of Gram negative isolates

\begin{tabular}{|c|c|c|c|c|c|c|c|}
\hline \multirow{2}{*}{ Antibiotics } & \multicolumn{2}{|c|}{ Sensitive } & \multicolumn{2}{|c|}{ Intermediate } & \multicolumn{2}{|c|}{ Resistant } & \multirow{2}{*}{ Total } \\
\hline & No. & $\%$ & No. & $\%$ & No. & $\%$ & \\
\hline Ciprofloxacin & 40 & 25.3 & 2 & 1.3 & 116 & 73.4 & 158 \\
\hline Ofloxacin & 41 & 25.9 & 3 & 1.9 & 114 & 72.2 & 158 \\
\hline Ceftriaxone & 5 & 6.1 & I & 1.22 & 76 & 92.68 & 82 \\
\hline Ceftazidime & 4 & 5.26 & 0 & 0 & 72 & 94.74 & 76 \\
\hline Gentamicin & 78 & 49.4 & 2 & 1.3 & 78 & 49.4 & 158 \\
\hline Amikacin & 101 & 63.9 & 14 & 8.9 & 43 & 27.2 & 158 \\
\hline Chloramphenicol & 52 & 32.9 & 8 & 5.1 & 98 & 62.6 & 158 \\
\hline Cefoperazone/ Sulbactum & 77 & 48.7 & 31 & 19.6 & 50 & 31.6 & 158 \\
\hline Meropenem & 47 & 37.9 & 10 & 8.07 & 67 & 54.03 & 124 \\
\hline Imipenem & 97 & 78.22 & 12 & 9.68 & 15 & 12.1 & 124 \\
\hline Piperacillin/ Tazobactam & 42 & 33.87 & 23 & 18.55 & 59 & 47.58 & 124 \\
\hline Colistin & 50 & 100 & 0 & 0 & 0 & 0 & 50 \\
\hline
\end{tabular}

Out of 47 isolates of $S$. aureus, $95.7 \%$ showed sensitivity towards chloramphenical, clindamycin, and cloxacillin. Penicillin G was ineffective (100\%), followed by amoxycillin (89.4\%). Among the $S$. aureus isolates, two isolates were found to be methicillin resistant $S$. aureus (MRSA), sensitive to vancomycin (Table 9).

The effective antibiotics against Pseudomonas spp. were amikacin with (68.4\%) sensitivity and gentamicin with (63.2\%) respectively. The most ineffective antibiotic was ceftazidime (94.7\%) (Table 10).

The most effective antibiotics against $A$. baumannii isolates was colistin with $100 \%$ sensitivity, the opposite was ceftriaxone with $100 \%$ respectively. Out of the isolates, more than $92 \%$ were resistant to ciprofloxacin, ofloxacin, gentamicin, cefoperazone/ sulbactum and piperacillin/ tazobactam (Table 11).

Out of 220 bacterial isolates, 138 were found to be the MDR isolates. The higher MDR pattern was found in Gram negative isolates $106(48.18 \%)$ than in Gram positive isolates 32 (14.55\%). The highest percentage $(96 \%)$ of MDR pattern was shown by $A$. baumannii followed by $K$. pneumoniae and the least $(21.92 \%)$ by $E$. coli (Table 12). 
Table 9 Antibiotic susceptibility of S. aureus

\begin{tabular}{|c|c|c|c|c|c|c|c|}
\hline \multirow{2}{*}{ Antibiotic } & \multicolumn{2}{|c|}{ Sensitive } & \multicolumn{2}{|c|}{ Intermediate } & \multicolumn{2}{|c|}{ Resistant } & \multirow{2}{*}{ Total } \\
\hline & No & $\%$ & No & $\%$ & No & $\%$ & \\
\hline Ciprofloxacin & 16 & 34 & 6 & 12.8 & 25 & 53.2 & 47 \\
\hline Ofloxacin & 16 & 34 & 6 & 12.8 & 25 & 53.2 & 47 \\
\hline Ceftriaxone & 37 & 78.7 & 6 & 12.8 & 4 & 8.5 & 47 \\
\hline Gentamicin & 29 & 61.7 & I & 2.1 & 17 & 36.2 & 47 \\
\hline Chloramphenicol & 45 & 95.7 & 0 & 0 & 2 & 4.3 & 47 \\
\hline Cefoperazone/ Sulbactum & 23 & 92 & I & 4 & I & 4 & 25 \\
\hline AmoxYcillin & 5 & 10.6 & 0 & 0 & 42 & 89.4 & 47 \\
\hline Erythromycin & 27 & 57.4 & 4 & 8.5 & 16 & 34 & 47 \\
\hline Clindamycin & 45 & 95.7 & 0 & 0 & 2 & 4.3 & 47 \\
\hline Cloxacillin & 45 & 95.7 & 0 & 0 & 2 & 4.3 & 47 \\
\hline Vancomycin & 2 & 100 & 0 & 0 & 0 & 0 & 2 \\
\hline
\end{tabular}

Table 10 Sensitivity pattern of Pseudomonas spp. to different antibiotics

\begin{tabular}{|c|c|c|c|c|c|c|c|}
\hline \multirow{2}{*}{ Antibiotics } & \multicolumn{2}{|c|}{ Sensitive } & \multicolumn{2}{|c|}{ Intermediate } & \multicolumn{2}{|c|}{ Resistant } & \multirow{2}{*}{ Total } \\
\hline & No. & $\%$ & No. & $\%$ & No. & $\%$ & \\
\hline Ciprofloxacin & 24 & 31.6 & 0 & 0 & 52 & 68.4 & 76 \\
\hline Ofloxacin & 25 & 32.9 & 0 & 0 & 51 & 67.1 & 76 \\
\hline Ceftazidime & 4 & 5.3 & 0 & 0 & 72 & 94.7 & 76 \\
\hline Gentamicin & 48 & 63.2 & I & 1.3 & 27 & 35.5 & 76 \\
\hline Amikacin & 52 & 68.4 & 10 & 13.2 & 14 & 18.4 & 76 \\
\hline Chloramphenicol & 14 & 18.4 & 3 & 3.9 & 59 & 77.6 & 76 \\
\hline Cefoperazone/ Sulbactum & 37 & 48.7 & 22 & 28.9 & 17 & 22.4 & 76 \\
\hline Meropenem & 19 & 31.67 & 2 & 3.33 & 39 & 65 & 60 \\
\hline Imipenem & 55 & 91.67 & 2 & 3.33 & 3 & 5 & 60 \\
\hline Piperacillin/ Tazobactam & 21 & 35 & 15 & 25 & 24 & 40 & 60 \\
\hline Colistin & 24 & 100 & 0 & 0 & 0 & 0 & 24 \\
\hline
\end{tabular}

Table I I Antibiotic susceptibility pattern of A. baumannii

\begin{tabular}{llllllll}
\hline \multirow{2}{*}{ Antibiotics } & \multicolumn{3}{c}{ Sensitive } & \multicolumn{3}{c}{ Intermediate } & \multicolumn{2}{c}{ Resistant } & \multirow{2}{*}{ Total } \\
\cline { 2 - 7 } & No & $\%$ & No & $\%$ & No & $\%$ & \\
\hline Ciprofloxacin & $\mathrm{I}$ & 4 & 0 & 0 & 24 & 96 & 25 \\
Ofloxacin & $\mathrm{I}$ & 4 & 0 & 0 & 24 & 96 & 25 \\
Ceftriaxone & 0 & 0 & 0 & 0 & 25 & 100 & 25 \\
Gentamicin & 2 & 8 & 0 & 0 & 23 & 92 & 25 \\
Amikacin & 3 & 12 & 3 & 12 & 19 & 76 & 25 \\
Chloramphenicol & $\mathrm{I}$ & 4 & 3 & 12 & 21 & 84 & 25 \\
Cefoperazone/ Sulbactum & 2 & 8 & 0 & 0 & 23 & 92 & 25 \\
Meropenem & 3 & 12 & 5 & 20 & 17 & 68 & 25 \\
Imipenem & 6 & 24 & 8 & 32 & 11 & 44 & 25 \\
Piperacillin/ & $\mathrm{I}$ & 4 & $\mathrm{I}$ & 4 & 23 & 92 & 25 \\
Tazobactam & & & & & & & \\
Colistin & 23 & 100 & 0 & 0 & 0 & 0 & 25 \\
\hline
\end{tabular}

Table 12 Distribution of MDR pathogens among total isolates

\begin{tabular}{llll}
\hline \multirow{2}{*}{ Organisms } & \multirow{2}{*}{ No. of Isolates } & \multicolumn{2}{c}{ MDR Isolates } \\
\cline { 3 - 4 } & & Frequency & $\%$ \\
\hline S. aureus & 47 & 24 & 50 \\
CoNS & 12 & 6 & 51.06 \\
Streptococcus spp. & 2 & 1 & 50 \\
Enterococcus spp. & 1 & 1 & 100 \\
Pseudomonas spp. & 76 & 52 & 68.42 \\
E. coli & 26 & 7 & 26.92 \\
Acinetobacter Baumannii & 25 & 24 & 96 \\
E. aerogens & 18 & 13 & 72.22 \\
K. pneumoniae & 10 & 9 & 90 \\
C. freundii & 3 & 1 & 33.33 \\
Total & 220 & 138 & 62.73 \\
\hline
\end{tabular}

Citation: Mahat P, Manandhar S, Baidya B. Bacteriological profile of wound infection and antibiotic susceptibility pattern of the isolates. J Microbiol Exp. 2017;4(5): I I9-I22. DOI: 10.15406/jmen.2017.04.00I26 
Among the 160 isolates from in-patients, $96(60 \%)$ were MDR strains and out of 60 out-patient, $42(70 \%)$ were found to be MDR strains, were statistically insignificant $(\mathrm{P}=0.172)$ (Table 13). Out of 172 isolates from male $103(59.88 \%)$ were MDR strains and among 48 isolates from female patients, $35(72.92 \%)$ were MDR strains, were statistically insignificant $(\mathrm{P}=0.99)$ (Table 14).

Table 13 Distribution of MDR pathogens among in-patient and out-patient

\begin{tabular}{lllll}
\hline Types of & \multirow{2}{*}{$\begin{array}{l}\text { Total } \\
\text { patient }\end{array}$} & \multicolumn{2}{l}{ MDR isolates } & \multirow{2}{*}{ P-Value } \\
\cline { 3 - 4 } & isolates & Frequency & $\%$ & \\
\hline In-patient & 160 & 96 & 60 & 0.172 \\
Out-patient & 60 & 42 & 70 & \\
Total & 220 & 138 & 62.73 & \\
\hline
\end{tabular}

Table 14 Gender-wise distribution of MDR pathogens

\begin{tabular}{lllll}
\hline \multirow{2}{*}{ Gender } & \multirow{2}{*}{ Total isolates } & \multicolumn{2}{l}{ MDR isolates } & \multirow{2}{*}{ P-Value } \\
\cline { 3 - 4 } & & Frequency & $\%$ & \\
\hline Male & 172 & 103 & 59.88 & 0.99 \\
Female & 48 & 35 & 72.92 & \\
Total & 220 & 138 & 62.73 & \\
\hline
\end{tabular}

\section{Discussion}

Out of 503 samples, 220 (43.7\%) showed bacterial growth. In similar studies by Maharjan. ${ }^{12}$ showed similar result $50.95 \%$ growth but by Puyal. ${ }^{13}$ showed $71.84 \%$ growth. The lesser percentage of growth positive cases may be due to the collection of samples from patients taking antibiotics.

The occurrence of higher number of male patients $370(73.56 \%)$ than female patients for the collection of pus samples may be due to the higher involvement of males in physical outdoor works for earning livelihood as compared to females and more chances of accidents during the activities. The higher growth positive cases in male patients $(78.18 \%)$ than in female $(21.82 \%)$ was observed in this study and was supported by the similar studies carried out by KC et al. ${ }^{7} \&$ Shrestha. ${ }^{14}$

The higher number of bacterial growth was observed in in-patients $160(72.73 \%)$ than in out-patients $60(27.27 \%)$. Similarly, Acharya ${ }^{15}$ \& Bhattrai ${ }^{16}$ also reported the higher number of growth positive cases in in-patients. This may be due to the factors associated with acquisition of nosocomial pathogens in in-patients and immunologically weak health status facilitates the wound infection in them.

The highest positive cases $30.45 \%$ (67/226) were observed in the age group of 21-30 years might be due to the active participation of this age group of people in different physical and mechanical works and during they may get injured.

Among the total 220 bacterial isolates, $71.82 \%$ were Gram negative and $28.18 \%$ were Gram positive bacteria. In similar study conducted by Yakha et al. ${ }^{17} \&$ Acharya ${ }^{15}$ Gram negative bacteria were found predominant. Isolation of Gram negative bacteria, during this study was higher, as they are more prevalent aerobes and facultative anaerobes in abscesses and skin wound, these bacteria have well recognized property for abscess formation in open as well as in visceral infection, which increases their incidence in both open and closed types of wound. Isolation of Gram negative bacteria also increases in the cases of Hospital acquired infections (HAIs). A study conducted by Banjara ${ }^{18}$ at TUTH showed the high rate of Gram negative bacteria in HAI.

Altogether, 10 different bacterial species were isolated with Pseudomonas spp. being the predominant one (34.55\%) followed by S. aureus (21.36\%), E. coli (11.82\%), A. baumannii (11.36\%), E. aerogens $(8.18 \%)$ Coagulase negative Staphylococci (CoNS) (5.45\%), K. pneumoniae (4.55\%), C. freundii (1.36\%), Streptococcus spp $(0.91 \%)$ and Enterococcus spp $(0.46 \%)$. Similar studies carried out by Hani and Adnan ${ }^{19} \&$ Ranjan et al. ${ }^{20}$ also showed Pseudomonas spp. was the most prevalent bacteria among the total cases with $27.8 \%$ and $29.6 \%$ respectively. But, the study conducted by Zafar et al. ${ }^{21}$ showed Pseudomonas spp. the second commonest bacteria with $18.35 \%$ and $S$. aureus as the most predominant isolates with $41.28 \%$ of the total cases. Pseudomonas spp was predominant (36.25\%) among in-patients followed by $A$. baumannii $(15.63 \%)$ but $S$. aureus was the most prevalent (40\%) among out-patients. All the isolates of $A$. baumannii isolated from in-patients.

Regarding antibiotic susceptibility testing, chloramphenicol $(93.5 \%)$ and amikacin $(63.9 \%)$ were the most effective antibiotics, in general to the Gram positive and Gram negative bacteria respectively. Among $47 \mathrm{~S}$. aureus, two were found to be methicillin resistant (MRSA). $89.4 \%$ of $S$. aureus were resistant to amoxycillin. The resistance of $S$. aureus to $\beta$ - lactam antibiotics is due to the production of penicillinas that hydrolyzed the $\beta$-lactam ring. MRSA resistance to $\beta$-lactam antibiotics is conferred primarily by the production of a bacterial cell wall penicillin binding protein, PBP2a. This has low binding to $\beta$-lactams which allows the organism to survive and multiply. PBP2a production is mecA gene encode. ${ }^{9} 51.06 \%$ (24/47) $S$. aureus isolates were MDR. The studies by Puyal ${ }^{13}$, Acharya ${ }^{15}$ and Bhattarai ${ }^{16}$ support this result.

In present study, out of 76 Pseudomonas spp. isolates, 52 (68.42\%) were found to be MDR isolates. Colistin was absolutely effective antibiotic against Pseudomonas spp. followed by imipenem (91.67\%), amikacin $(68.4 \%)$ and gentamicin $(63.2 \%)$ respectively. ceftazidime was found to be the most ineffective (94.7\%) antibiotics. Similar study by Acharya ${ }^{15}$ found $62.16 \%$ MDR among Pseudomonas spp. isolates and amikacin was found to be $84.61 \%$ effective antibiotics. The study by Hani and Adnan ${ }^{19}$ showed amikacin and gentamicin effectiveness, $78 \%$ and $72 \%$ respectively against Pseudomonas spp. But the study carried out by Falagas et al..$^{22}$ isolated the organism from ICU patients which was almost resistant to amikacin, gentamicin and other antipseudomonal antibiotics. The study conducted by $\mathrm{Li}$ et al. ${ }^{23}$ showed that active efflux played role in the resistance to various non- $\beta$-lactam agents by Pseudomonas spp. strains and de-energization by the addition of a proton conductor increased the accumulation level to that expected for equilibration across the cytoplasmic membrane.

In this study, A. baumannii constituted 25 (15.82\%) of the Gram negative isolates and $11.82 \%$ among the total bacterial isolates. Among the isolated A. baumannii $24(96 \%)$ were found to be MDR strains. In the study conducted by Kelper et al. ${ }^{24}$, out of 237 samples 38 (16.03\%) were found to be Acinetobacter spp. out of which 29 (76.31\%) isolates were found to be MDR. Almost all the antibiotics used in this study were found to be resistant to the organism. However, the imipenem and meropenem were effective $24 \%$ and $12 \%$ respectively against the A. baumannii. MDR A. baumannii is an important nosocomial pathogen. It has the capacity to survive in dry environments, which increases the risk for nosocomial transmission. A. baumannii can cause infection in any organ system, including bacteremia, pneumonia, endocarditis, meningitis, urinary tract infection, intra-abdominal abscess, osteomyelitis, soft tissue infection, surgical site infections. ${ }^{25}$

The prevalence of MDR isolates was found independent of gender and types of patients. Imipenem was found to be the most effective antibiotic for Gram negative bacteria from in-patients. $P$. 
aeruginosa and $S$. aureus were found as the most frequent etiological agents from pus samples. The prevalence of MDR was found to be $62.7 \%$ (138/220) among the total bacterial isolates. All the $A$. baumannii were isolated from in-patients and almost $96 \%(24 / 25)$ were found to be MDR. The result obtained from this study will be helpful for policy makers in evaluating the infection control measures in hospitals. The routine antimicrobial susceptibility testing before antibiotic administration is highly recommended since it can play key role to limit the wound infections to minimum as the emergence of drug resistant bacteria is less likely when there is empirical drug therapy, fasten the process of wound healing hence the appropriate use of drug decreases the cost of wound infection treatment.

\section{Conflicts of interest}

There is no conflict of interest.

\section{Acknowledgements}

None.

\section{Funding}

None.

\section{References}

1. Bowler P, Durden B, Armstrong D. Wound Microbiology and Associated Approaches to Wound Management. Clin Microbiol Rev. 2001;14(2):244-269.

2. Church D, Elsayed S, Reid O, et al. Burn wound infection. Clin Microbiol Rev. 2006;19:403-434.

3. Gupta N, Gautam V, Saini S, et al. Prevalence of multi drug resistant organism in wound infection. $J$ Infect Dis Antimicrobial Agent. 2002;19:111-117

4. Esebelahie NO, Esebelahie FO, Omoregie R. Aerobic bacterial isolates from wound infection. Afr J Cln Exper Microbial. 2013;14(3):155-159.

5. Nichole RE. Preventing surgical site infection: a surgeon's perspective. Emerg Infect Dis. 2001;7(2):220-224.

6. Thomas KH. Surgical Wound Infection, an overview. Am J Med. 1981;70(3):712-718.

7. KC R, Shrestha A, Sharma VK. Bacteriology Study of Wound Infection and Antibiotic susceptibility Oattern of Isolates. Nepal Journal of Science and Technology. 2013;14(2):143-150.

8. Gottrup F, Melling A, Hollander D. An overview of surgical site infections: aetiology, incidence and risk factors. EWMA Journal. 2005;5(2):11-15.

9. Cheesbrough M. District Laboratory Practice in Tropical Countries. Part 2, Cambridge University Press, India. 2000:124-132.

10. CLSI. Performance standards foe antimicrobial susceptibility testing twenty-first informational supplement. 2011;31(1):M100-S21.
11. Magiorakos AP, Srinivasan A, Carey RB, et al. Multidrug-resistant, extensively drug-resistant and pandrug-resistant bacteria: an international expert proposal for interim standard definitions for acquired resistance. Clin Microbiol Infect. 2012;18(3):268-281.

12. Maharjan S. Bacteriology of Wound Infection Among patients Visiting B \&B Hospital and Antibiotic Sensitivity Profile of the Isolates. M.Sc. dissertation submitted to the department of Microbiology, Nepal. 2009.

13. Phuyal K. Bacteriology of Wound Infection with Reference to Multi Drug Resistant Isolates. M.Sc. dissertation submitted to the Department of Microbiology, Nepal. 2008.

14. Shrestha P. Bacteriology of Wound Infection and their Antibiotic Susceptibility Pattern. M.Sc. dissertation submitted to the Department of Microbiology, Nepal. 2013.

15. Acharya S. Multi Drug Resistant of bacterial Isolates from wound Infection. M.Sc. dissertation submitted to the Department of Microbiology, Nepal. 2012.

16. Bhattarai S. Microbiological Profile of Wound Infection and their Antibiotic Susceptibility pattern. M.Sc. dissertation submitted to the Department of Microbiology, National College, Kathmandu Nepal. 2013.

17. Yakha JK, Sharma AR, Dohal N, et al. Antibiotic Susceptibility Pattern of Bacterial Isolates Causing Wound Infection Amongthe Patients Visiting B \& B Hospital. Nepal Journal of Science and Technology. 2014;15(2):91-96.

18. Banjara MR. Study of Air, Water and Wound Infection in Different Wards of TUTH. M.Sc. dissertation submitted to the Central Department of Microbiology, Nepal. 2002.

19. Hani AM, Adnan SJ. Incident of Pseudomonas aeruginosa in Postperative Wound Infection. Am J Infect Dis. 2009;5(1):1-6.

20. Ranjan KP, Ranjan N, Bansal SK, et al. Prevalence of Pseudomonas aeruginosa in Post-operative Wound Infection in a Referral Hospital in Haryana, India. J Lab Physicians. 2011;2(2):74-77.

21. Zafar A, Anwar N, Ejaz H. Bacteriology of Infected Wounds- A Study Conducted at Children Hospital Lahore. Biomedicavol. 2011;23:1.

22. Flagas ME, loannis AB, Sofia KK, et al. Outcome of Infection Due to Pandrug-resistant (PDR) Gram Negative Bacteria. BMC infect Dis. 2005;5:24.

23. Li XZ, Ma D, Livermore DM, et al. Role of Efflux Pump(s) in Intrinsic Resistance of Pseudomonas aeruginosa: Active Efflux as a Contributing Factor to $\beta$-Lactam Resistance. Antimicrob Agents Chemother. 1994;8(8):1742-1752.

24. Davis KA, Moran KA, McAllister CK, et al. Multidrug Resistant Acinetobacter Extremity Infections in Soldiers. Emerg Infect Dis. 22005;11(8):1218-1224.

25. Brooks GF, Carroll KC, Butel JS, et al. Jawez, Melnick and Adelberg's Medical Microbiology. (24 $4^{\text {th }}$ edn), MC Graw Hill Companies, New York, USA. 2007;263-270. 